\title{
A near miss: an uncommon injury following a common mechanism
}

\author{
David Bryson, Zeeshan Khan, Randeep Aujla, James David Bromage
}

Trauma and Orthopaedics Department, Kettering General Hospital, Kettering, Northamptonshire, UK

Correspondence to Dr David Bryson, davidjbryson@hotmail.com

\begin{abstract}
Summary
Subtalar dislocation is an uncommon injury involving the simultaneous dislocation of the talocalcaneal and talonavicular joints. Radiographic images can be difficult to interpret for the inexperienced clinician because of the obliquity of the foot and the overlap of tarsal bones. The authors describe the case of a 24-year-old male who presented to the emergency department (ED) with a painful left foot and ankle following a twisting injury. He was examined by a junior member of the ED team and diagnosed with a left ankle sprain. Preparations were underway for discharge home when the radiographs, described as 'normal but somewhat strange', were shown to the orthopaedic senior house officer who happened to be in the ED. The patient was subsequently reviewed by the orthopaedic registrar and diagnosed with a medial subtalar dislocation. He was then taken to theatre for closed reduction and application of a below-knee cast.
\end{abstract}

\section{BACKGROUND}

Subtalar dislocations are very rare injuries accounting for $1 \%$ of all dislocations ${ }^{1}$. They can be anterior, posterior, medial or lateral based on the direction of displacement of the foot on the calcaneus ${ }^{2}$. Medial dislocations are caused by forceful inversion of the foot. The neck of the talus pivots on the sustenaculum tali resulting in dislocation of the talonavicular joint followed by dislocation of the subtalar joint ${ }^{3}$. The patient presents with the foot plantarflexed and supinated in a position that has been described as 'basketball foot' after Graham reported four cases of medial subtalar dislocations in young US military personnel who sustained inversion injures playing basketball ${ }^{4}$.

In this instance the dislocation was overlooked by a junior emergency department (ED) doctor with limited experience in the assessment of musculoskeletal injures and associated radiographic images. The complicating issue with this patient was that on the contralateral side he had a similarly 'twisted foot', which is why the junior doctor considered this to be a benign foot and ankle sprain on the involved side. In the busy environment of the ED it is easy to rigidly adhere to the mantra that 'common things are common' and resort to gestalt diagnosis. The mechanism of injury and presentation was consistent with that of an ankle sprain. However, the degree of bony deformity and the radiographic images should have raised concern on the part of the junior doctor. This case represents a 'near miss' of a significant injury that could have had serious longterm consequences for a young patient. It also illustrates the importance of seeking senior help or specialty specific guidance with unusual or atypical presentations or in cases where uncertainty over clinical or investigative findings exists.

\section{CASE PRESENTATION}

A 24-year-old fit and well male patient presented to the ED late on friday night following a forced plantar flexion and inversion injury to the left foot while climbing out of his car. He was fully compos mentis and non-weight bearing on the affected side.

On examination the left foot was plantarflexed and supinated. There was no significant swelling, ecchymosis or neurovascular deficit. Interestingly, he was noted to have a very mild and easily correctible clubfoot deformity on the right side. Inspection from the foot-end of the bed revealed no difference in the position of affected and contralateral limb. His medical and surgical history was unremarkable. He was a smoker since the age of 14 and consumed 14-21 units of alcohol a week. There was no family history of joint or connective tissue disorders.

\section{INVESTIGATIONS}

Antero-posterior and lateral radiographs of the foot and ankle (figures 1 and 2).

\section{TREATMENT}

Reduction under conscious sedation with midazolam and morphine was attempted in the ED resuscitation bay. This was unsuccessful and the patient was taken to operating theatre for closed reduction under anaesthesia with preparation for open reduction and fixation if required. Closed reduction was successful and confirmed with image intensifier radiography (figure 3). The joint was found to be stable and the patient furnished with a below knee non-weight bearing cast and kept over night for neurovascular observations. He made an uneventful recovery and was discharged home the next morning with a follow-up arranged in the fracture clinic in 1 week with plain radiography (figure 4).

\section{OUTCOME AND FOLLOW-UP}

The patient has made full recovery and returned to his preinjury functional status. He has been discharged from our clinic. 


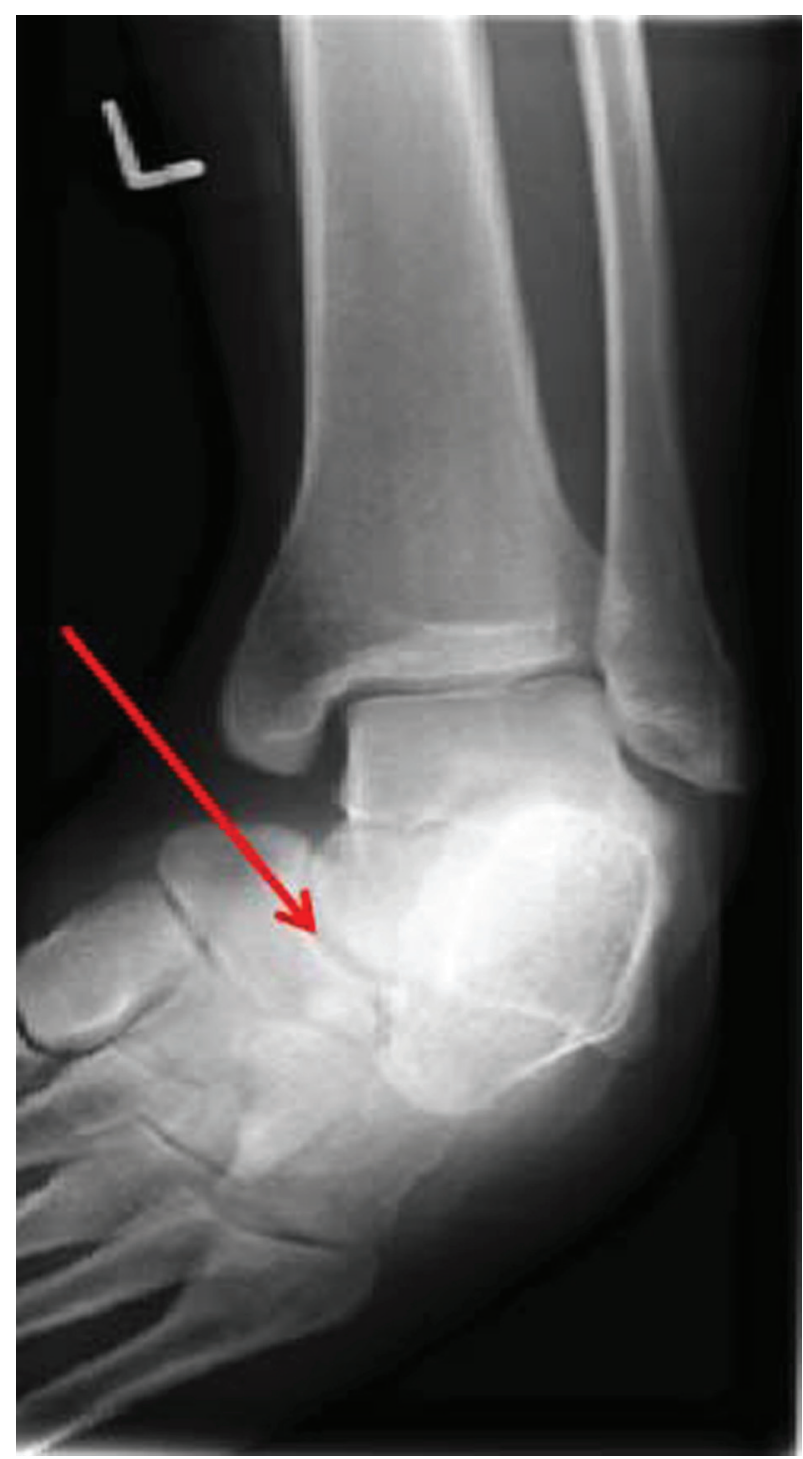

Figure 1 Anterioposterior radiograph of left foot demonstrating medial dislocation of the midfoot (highlighted by red arrow). This is the radiograph that was described as 'normal but somewhat strange'.

\section{DISCUSSION}

Subtalar dislocation was first described two centuries ago in 1811 by Judcy and Dufaurents separately ${ }^{5}$. In 1964 Grantham reported five cases of medial subtalar dislocations sustained during athletic participation. Forceful inversion was the mechanism of injury in each case with four of the five dislocations sustained while playing basketball, prompting Grantham to describe the injury as 'basketball foot'4. In each case closed reduction and plaster immobilisation was employed to good effect.

$50-100 \%$ of subtalar dislocations are associated with a fracture $^{6}$, including fractures of the malleoli, osteochondral fractures of the talonavicular or talocalcaneal joints and base of the fifth metatarsal ${ }^{7}$. Our patient did not have any evidence of co-existing fractures of the foot and ankle or osteochondral fractures. Prompt reduction, as with any dislocation, is a tenet of initial management in order to minimise further soft tissue and neurovascular injury ${ }^{6}$.

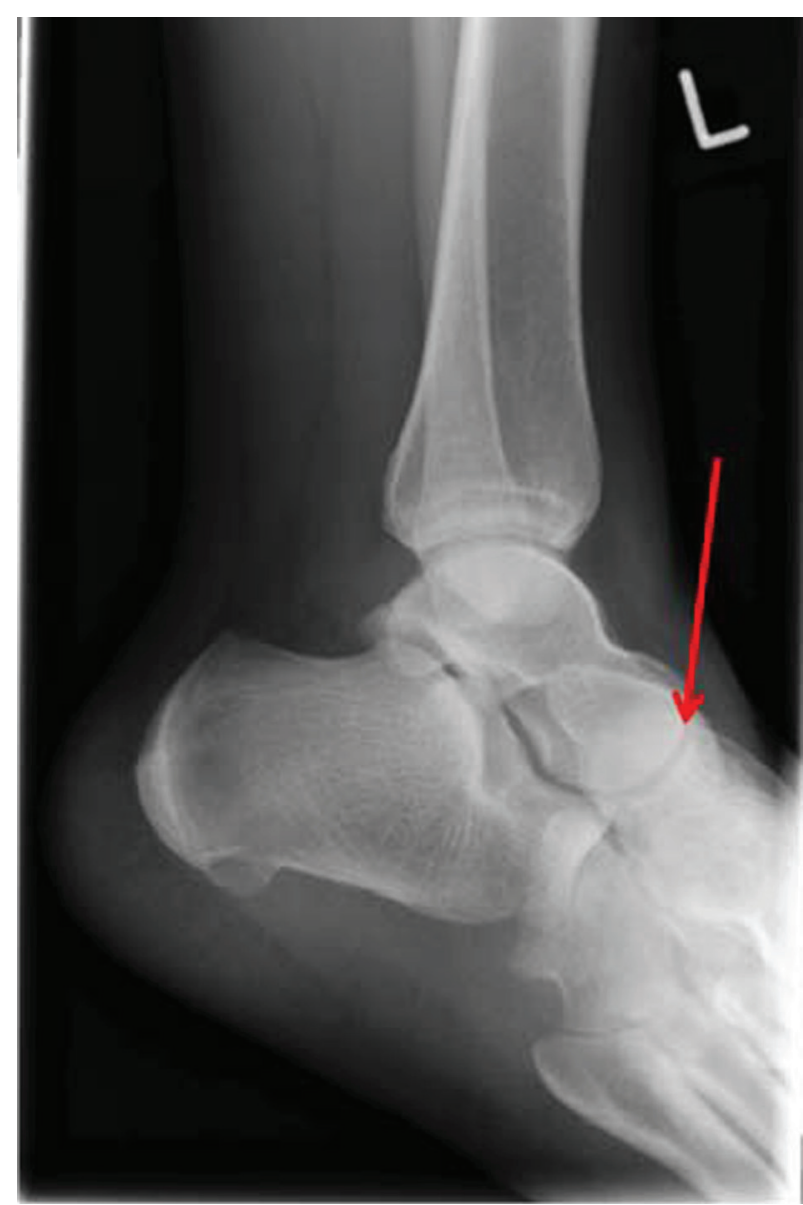

Figure 2 Lateral radiograph demonstrating disruption of talonavicular joint (red arrow).

Closed reduction is successful in $80-90 \%$ of medial and lateral dislocations ${ }^{7}$ with minimal long-term disability seen in those with uncomplicated dislocations who undergo prompt management ${ }^{5}$. Potential complications of subtalar dislocations include post-traumatic arthritis, osteonecrosis and subtalar ankylosis ${ }^{6}$ and are more likely to manifest when there is a failure to diagnose and reduce the dislocation promptly ${ }^{5}$. Fortunately for our patient, the risk of such complications was minimised by the prompt actions instituted by the orthopaedics on call team. However, had the patient been discharged home, as was the original ED management plan, the outcome could have been much different.

Musculoskeletal conditions account for at least 10\% of consultations in general practice ${ }^{8}$ and $20 \%$ of emergency room attendances ${ }^{9}$. For many doctors, including the ED senior house officer who first examined this patient, undergraduate teaching represents their only exposure to orthopaedic surgery and musculoskeletal medicine $e^{9}$. The situation is particularly challenging in the time-pressured environment of the ED where patients are managed by junior doctors with limited clinical exposure to musculoskeletal disorders and associated radiographic images. This is frequently compounded by a lack of senior support during antisocial hours. Until recently the ED in our own institution did not have registrar cover between the hours of $2 \mathrm{am}$ and 


\section{BMJ Case Reports}

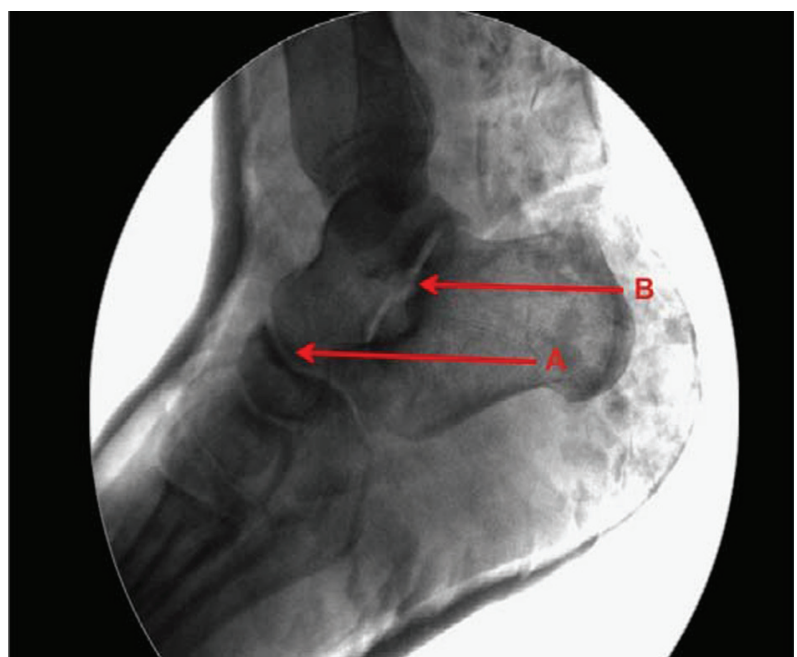

Figure 3 Image intensifier postreduction lateral view of patient in $s$ backslab showing well reduced talonavicular $(A)$ and talocalcaneal (B) joints.

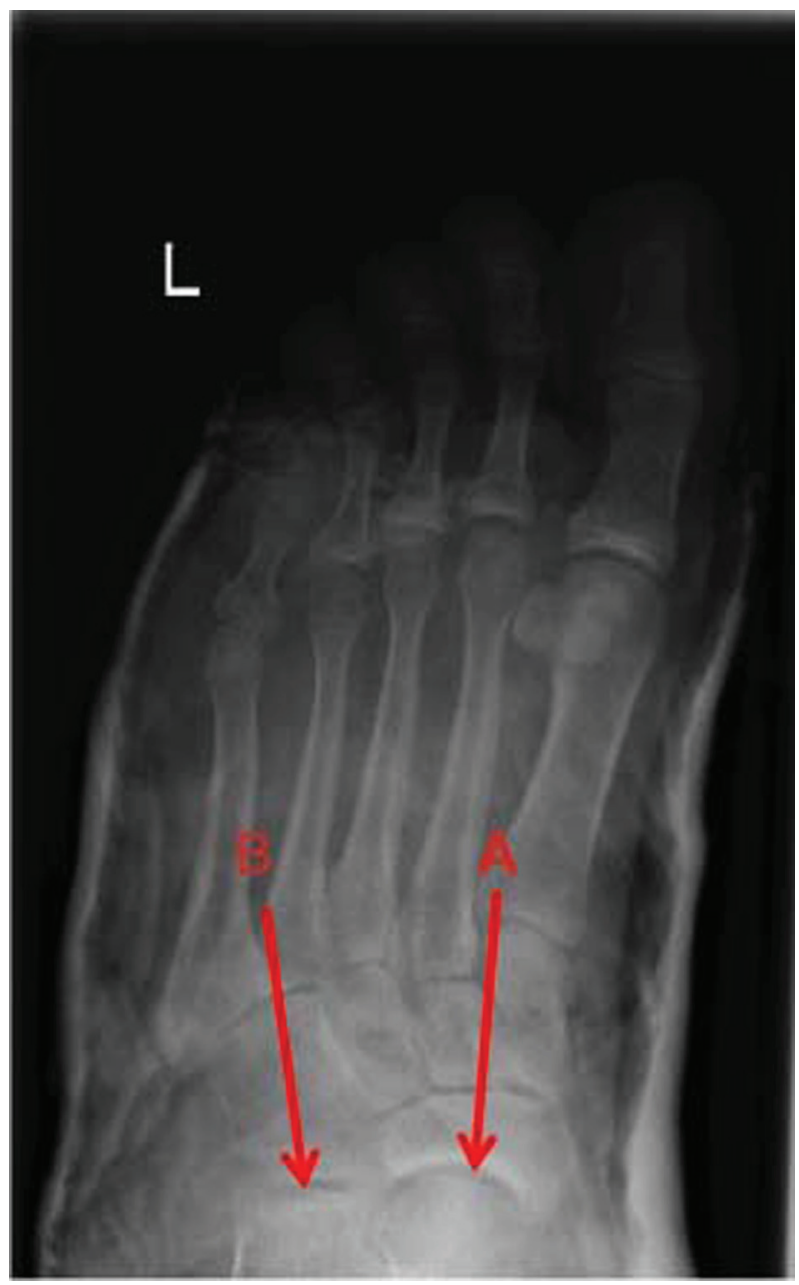

Figure 4 Oblique view of the patient in plaster showing a well reduced mid-foot: (A) talonavicular joint, $(B)$ calcaneocuboid joint.
$8 \mathrm{am}$. Consequently, junior trainees were left unsupervised to manage all patients presenting to ED.

With an average duration of 5 weeks of orthopaedics and trauma exposure at undergraduate level ${ }^{8}$, it would be unreasonable to expect a junior trainee new to emergency medicine to have a sound knowledge of the anatomy of the subtalar joint and subtalar dislocations. As is the case with all medical disciplines, there is no substitute for experience. With repeated exposure to musculoskeletal ailments, correlation of clinical and investigative findings and a robust system for radiographic assessment, near misses such as the one described above may be kept to a minimum. In cases where uncertainty persists, junior doctors should not hesitate to seek senior or specialty specific input for assistance and guidance.

\section{Learning points}

- Be wary of making a diagnosis simply because it fits a recognised pattern

- Junior trainees should not hesitate to seek senior guidance when there is uncertainty over clinical or radiographic findings

- A consistent and robust system of radiographic interpretation and correlation with clinical findings is required in order to reduce the risk of missing visible fractures and uncommon injuries

Competing interests None.

Patient consent Obtained.

\section{REFERENCES}

1. Heppenstall RB, Farahvar H, Balderston R, et al. Evaluation and management of subtalar dislocations. J Trauma 1980;20:494-7.

2. DeLee JC, Curtis R. Subtalar dislocation of the foot. J Bone Joint Surg Am 1982;64:433-7.

3. Monson ST, Ryan JR. Subtalar dislocation. J Bone Joint Surg Am 1981;63:1156-8.

4. Grantham SA. medical subtalar dislocation: five cases with a common etiology. J Trauma 1964;4:845-9.

5. Hyder N, Jones S, Nair B. Medial subtalar dislocation. The Foot 1997;7:34-6.

6. Jungbluth $\mathbf{P}$, Wild $\mathrm{M}$, Hakimi $\mathrm{M}$, et al. Isolated subtalar dislocation. J Bone Joint Surg Am 2010;92:890-4.

7. Kinik H, Okty O, Arikan M, et al. Medial subtalar dislocation. Int Orthop 1999;23:366-7.

8. Williams SC, Gulihar A, Dias JJ, et al. A new musculoskeletal curriculum: has it made a difference? J Bone Joint Surg Br 2010;92:7-11.

9. Freedman KB, Bernstein J. The adequacy of medical school education in musculoskeletal medicine. J Bone Joint Surg Am 1998;80:1421-7. 


\section{BMJ Case Reports}

This pdf has been created automatically from the final edited text and images.

Copyright 2011 BMJ Publishing Group. All rights reserved. For permission to reuse any of this content visit http://group.bmj.com/group/rights-licensing/permissions.

BMJ Case Report Fellows may re-use this article for personal use and teaching without any further permission.

Please cite this article as follows (you will need to access the article online to obtain the date of publication).

Bryson D, Khan Z, Aujla R, Bromage JD. A near miss: an uncommon injury following a common mechanism. BMJ Case Reports 2011;10.1136/bcr.04.2011.4086, date of publication

Become a Fellow of BMJ Case Reports today and you can:

- Submit as many cases as you like

- Enjoy fast sympathetic peer review and rapid publication of accepted articles

- Access all the published articles

- Re-use any of the published material for personal use and teaching without further permission

For information on Institutional Fellowships contact consortiasales@bmjgroup.com

Visit casereports.bmj.com for more articles like this and to become a Fellow 